\title{
STUDY OF VISCOSITY OF AQUEOUS SOLUTIONS OF NATURAL POLYSACCHARIDES
}

\author{
Lyudmila K. Asyakina*, Lyubov S. Dyshlyuk
}

Kemerovo Institute of Food Science and Technology (University), Stroiteley blvd. 47, Kemerovo, 650056 Russian Federation

Received May 1, 2016;

Accepted in revised form June 5, 2016;

Published December 30, 2016

* e-mail: alk_kem@mail.ru

\begin{abstract}
One of the steps of synthesis of biodegradable polymers is preparation of an aqueous solution of raw materials. Formulation of biodegradable films with optimum characteristics requires to undertake a separate rheological study of each aqueous solution. An essential parameter in this step is a uniform thickness, which is achieved by means of specified viscosity parameters. Viscosity of solutions depends on many parameters, among which are composition and concentration of components in a solution, solution preparation temperature, $\mathrm{pH}$ of the finished medium, and presence of free ions. This article describes studies and results on study of viscosity parameters of aqueous solutions of natural polysaccharides: agar-agar, hydroxypropyl methyl cellulose and carrageenan. For aqueous solutions of carrageenan and hydroxypropyl methylcellulose, viscosity was measured at $25^{\circ} \mathrm{C}$. In addition, viscosity parameters were measured for $1.5 \%$ hhydroxypropyl methylcellulose solutions at $40^{\circ} \mathrm{C}$ and $60^{\circ} \mathrm{C}$. Depending on the gel formation temperature, viscosity of agar-agar solutions was measured at $50^{\circ} \mathrm{C}$ or $70^{\circ} \mathrm{C}$. According to the results of experiments, it was found that viscosity of $1.0-1.5 \%$ hydroxypropyl methylcellulose aqueous solutions is in the range of $8.0-80.0 \mathrm{cP}$. Heating to $100^{\circ} \mathrm{C}$ at $\mathrm{pH} 6$ results in irreversible destruction of hydroxypropylmethylcellulose molecules. Aqueous solutions of agar-agar are similar to hydroxypropyl methylcellulose solutions but agar-agar is able to gelate at sufficiently low concentrations (from $0.5 \%$ ). Viscosity of $3.0-5.0 \%$ carrageenan aqueous solutions varies within a wide range: $1.5-1400.0 \mathrm{cP}$. Thus, rheological properties allow to adjust viscosity of the process mixture in the production of biodegradable polymers in the desired range and in different directions.
\end{abstract}

Keywords: biodegradable film, polysaccharides, rheology, solution viscosity, shear rate gradient

DOI: $10.21603 / 2500-1418-2016-1-2-11-19$.

\section{INTRODUCTION}

Preparation of biodegradable polymers involves preparation of an aqueous solution of the selected components. To obtain biodegradable films of uniform thickness, it is necessary to prepare a solution with a specified viscosity [1]. Viscosity of solutions generally depends on many factors, such as composition, concentration of components, solution temperature, $\mathrm{pH}$, presence of electrolytes in solution. Formulation of a solution with optimum characteristicsrequires to study rheological properties of aqueous solutions of individual components [2].

One of the most important parameters characterizing solutions of polymeric materials is the internal friction or viscosity of solution. This property demonstrates ability of flowable substance to put up a resistance when moving one piece relative to another inside them. This displacement results to a loss of energy expended against friction. There are two types of viscosity dynamic and kinematic. The dynamic viscosity is measured in poises $(\mathrm{P})$. One poise is equal to $0.1 \mathrm{~Pa}^{*} \mathrm{~s}$. The kinematic viscosity is measured in Stokes, $\mathrm{m}^{2} / \mathrm{s}$. Kinematic viscosity can also be expressed as the ratio of dynamic viscosity to density of material [3].
Rheology of macromolecular solutions has its own characteristics; their viscosity is generally higher than viscosity of solutions of low molecular substances and colloids of the same concentrations. The nature of the solvent greatly affects the shape of macromolecules which are inside it [4].

In case of average concentration polymer solutions, the current dependence of a velocity gradient on viscosity is caused by two reasons. Firstly, in the solution flow process long chain molecules which are in solution in the form of coiled coils, unfold and orientate according to the flow direction, thereby reducing the hydrodynamic drag [5]. In case of flow with large velocity gradients extension of molecular chains can be so large that eventually leads to rupture of macromolecules. Secondly, macromolecules in concentrated solutions can interact with each other and form fragments and associates of spatial grid which will strongly impede the flow. The higher the flow rate, the more these structures are destroyed, which also causes a decrease in drag of molecules, and thus the viscosity of solution [6].

When the temperature increases, traffic density of segments increases, which prevents formation of structures. In addition, the temperature increase leads to

Please cite this article in press as: Asyakina L.K., Dyshlyuk L.S. Study of viscosity of aqueous solutions of natural polysaccharides. Science Evolution, 2016, vol. 1, no. 2, pp. 11-19. doi: 10.21603/2500-1418-2016-1-2-11-19.

Copyright (C) 2016, KemSU. This is an open access article distributed under the terms of the Creative Commons Attribution 4.0 International License (http:// creativecommons.org/licenses/by/4.0/), allowing third parties to copy and redistribute the material in any medium or format and to remix, transform, and build upon the material for any purpose, even commercially, provided the original work is properly cited and states its license. This article is published with open access at http:// science-evolution.ru/ 
decrease in the true internal friction coefficient, which entails decrease in the solution viscosity parameters.

Decrease in viscosity of a high-molecular substance solution is not always caused by decrease in temperature. In addition, viscosity decrease is typical for solutions containing branched macromolecules which practically have no segmental type of movement. Sometimes, viscosity of solutions containing long, unbranched molecular chains may rise with the temperature increase, due to increase in the traffic density of segments preventing macromolecule orientation in the flow [7].

Viscosity of polymer solutions typically changes due to increase in their concentration. For polymer solutions, increase in concentration leads to very sharp increase in the solution viscosity along a curve which is convex to the concentration axis. One reason for the sharp increase in viscosity with concentration increase is formation of structures in the system [8].

Viscosity as well as osmotic pressure of sufficiently concentrated solutions of high-molecular substances can be influenced by the solution preparation method. And here such an effect is caused by a slow establishment of equilibrium in the system [9].

Solutions of high molecular weight substances in certain circumstances lose their fluidity, i.e, transform into gels. Gelation may occur inadvertently (spontaneously) due to temperature changes, by concentrating solution or by adding to it little amounts of electrolyte. Normally, under the influence of these factors, a structural viscosity of the system increases, which leads to the transformation of a liquid into a gel system, exhibiting a number of solid body properties [10].

As the temperature increases due to increase in intensity of microbrownian movement of individual segments and decrease in life and number of links between macromolecules, a gel structure breaks down [11]. Conversely, decrease in temperature induces gel formation processes, since in this case a spectrum of contacts between macromolecules shifts towards greater strength, and expands. The process of transformation of solution into gel and gel into solution under the influence of temperature changes occurs continuously, thus in this process there are no crystallization or melting temperatures [12].

Also, the $\mathrm{pH}$ of solution strongly influences the gelation ability of aqueous solutions of macromolecular compounds [13]. Gelation is more intense at a $\mathrm{pH}$ equal to the isoelectric point, since in this case the same number of oppositely charged ionized groups is throughout the molecular chain length, establishing links between macromolecules. As a result of $\mathrm{PH}$ change on either direction from the isoelectric point, macromolecules became identically charged that does not allow them to form links with each other. When adding large amounts of alkali or acid, ionization degree of groups capable to form ions is reduced, and gelation ability increases [14] again.

The most interesting features of conventional gels are their mechanical properties, in particular elasticity. Gel concentration significantly influences their mechanical properties. Gels containing a small number of permanent intermolecular links in the unit volume, are usually quite flexible. On the contrary, gels with a large number of links between macromolecules are relatively low flexible, because the more links between the polymer chains are, the less the possibility of changing the shape of a macromolecule, and the more rigid is the grid formed [15].

Most gel systems, being a part of plant and animal organisms possess anisotropic properties due to the conditions of formation of these gels. The reason of anisotropic properties of artificial gels is their uneven deformation in the course of formation or non-uniform drying shrinkage, such as a gel made from gelatin on a glass substrate. Shrinkage in these conditions occurs only over the thickness of the gel film, causing the gelatin macromolecules are oriented parallel to the substrate plane [16].

This article presents the results of a study of rheological properties of aqueous solutions of natural polysaccharides: agar-agar, carrageenan and hydroxypropyl methyl cellulose.

\section{OBJECTS AND METHODS OF STUDY}

The following concentrations of natural polysaccharide solutions were selected for the studies on the basis of literature data:

- agar-agar (Panreac, Germany), sample no. 1 $0.5 \%, 1.0 \%, 1.5 \%$;

- agar-agar(Helicon, USA), sample no. $2-0.5 \%$, $1.0 \%, 1.5 \%$;

- kappa-carrageenan (Boc Sciences, USA), sample no. $1-1.0 \%, 1.5 \%, 3.0 \%, 5.0 \%$;

- iota-carrageenan (Newgreen Pharmchem Co., China), sample no. 2 - 1.0\%, 1.5\%, 3.0\%, 5.0\%;

- hydroxypropyl methylcellulose, HPMC (Acros, Belgium), sample no. $1-0.5 \%, 1.0 \%, 1.5 \%$;

- hydroxypropyl methylcellulose, HPMC (Ashland Aqualon Functional Ingredients, USA), sample no. 2 $0.5 \%, 1.0 \%, 1.5 \%$.

This choice is caused by a number of valuable properties of these biopolymers, making them a promising material for improving the technology of biodegradable polymers.

In order to analyze rheological properties, solutions of samples were prepared with the use of deionized water. Thereafter, solutions were allowed to stand overnight at temperature of $4^{\circ} \mathrm{C}$. On the next day samples were stirred until complete dissolution of particles at room temperature. Then samples of $20 \mathrm{~mL}$ were taken from solutions. The samples were heated to $25^{\circ} \mathrm{C}$ and $100^{\circ} \mathrm{C}$ (carrageenan to $25^{\circ} \mathrm{C}$ ), and stirred for $5 \mathrm{~min}$. At the end they were cooled to a temperature of $25^{\circ} \mathrm{C}$.

Viscosity parameters in this study were measured using the Brookfield LVDV-II + Pro rotary type viscometer, based on the Couette method. Viscosity of HPMC and carrageenan aqueous solutions was measured at $25^{\circ} \mathrm{C}$. For $1.5 \%$ HPMC solutions, viscosity was also measured at $40^{\circ} \mathrm{C}$ and $60^{\circ} \mathrm{C}$. Viscosity of agaragar solutions was measured depending on a gelation temperature at $50^{\circ} \mathrm{C}$ or $70^{\circ} \mathrm{C}$. 
Samples were dissolved in a buffer mixture $(0.04 \mathrm{M}$ of phosphoric acid, $0.04 \mathrm{M}$ of acetic acid, $0.04 \mathrm{M}$ of boric acid) with the respective $\mathrm{pH}$ values $(5.0 ; 7.0 ; 8.5$; 10.0 for carrageenan, and 3.0, 5.0, 7.0 for agars) to study solutions viscosity dependence on $\mathrm{pH}$. For HPMC and agar-agar $1.5 \%$ solutions were used, for carrageenan 5\% solutions were used. If necessary, $\mathrm{pH}$ was adjusted to the desired value by addition $\mathrm{NaOH}$ or $\mathrm{HCl}$ after final dissolution of hydrocolloids.

To establish agar and carrageenan solutions viscosity dependence on the salt concentration $(\mathrm{NaCl})$, $1.5 \%$ solutions were prepared in $1 \%, 3 \%$ and $5 \% \mathrm{NaCl}$ solution with the use of deionized water.

All the above solutions were prepared similarly: they were stirred for 5 minutes at $75^{\circ} \mathrm{C}$, then were put in a water bath for 20 minutes at $100^{\circ} \mathrm{C}$. At the end they were permanently stirred at $70^{\circ} \mathrm{C}$.

\section{RESULTS AND DISCUSSION}

We have previously studied the rheological properties of solutions of natural polysaccharides since viscosity of solutions of high-molecular compounds may depend on the measurement procedure. Fig. 1 shows the dependence of characteristic viscosity of hydroxypropyl methylcellulose aqueous solutions on the shear rate gradient values during measurement.
From the Fig. 1 it follows that for the most HPMC solutions studied in this work, the shear rate gradient value does not vary by more than $5 \%$ depending on the characteristic viscosity. Based on this, we can conclude that these solutions behave as solutions with low molecular weight compounds. An aqueous solution of the sample no. 2 with a concentration of $1.5 \%$ is an exception, since their viscosity varies by more than $10 \%$ depending on measurement conditions. In addition, it is characteristic that values of characteristic viscosity for HPMC sample no. 1 are lower by $50 \%$ compared with the corresponding values for sample no. 2 .

Similar results were obtained for $1.5 \%$ agar-agar aqueous solutions. The characteristic viscosity of an aqueous solution of sample no. 1 varied up to $10 \%$ depending on the shear rate gradient. Depending on the measurement conditions, viscosity of the sample no. 2 aqueous solution varies by nearly $40 \%$ (Fig. 2). Characteristic viscosity values for the agar-agar sample no. 2 are $12.5 \%$ lower compared with those for sample no. 1 .

The shear rate gradient dependence on viscosity of $5.0 \%$ carrageenan aqueous solutions is shown in Fig. 3, from which it follows that, for 5.0\% carrageenan aqueous solutions, significant deviations from Newton's Law are observed. Viscosity of solutions varies up to

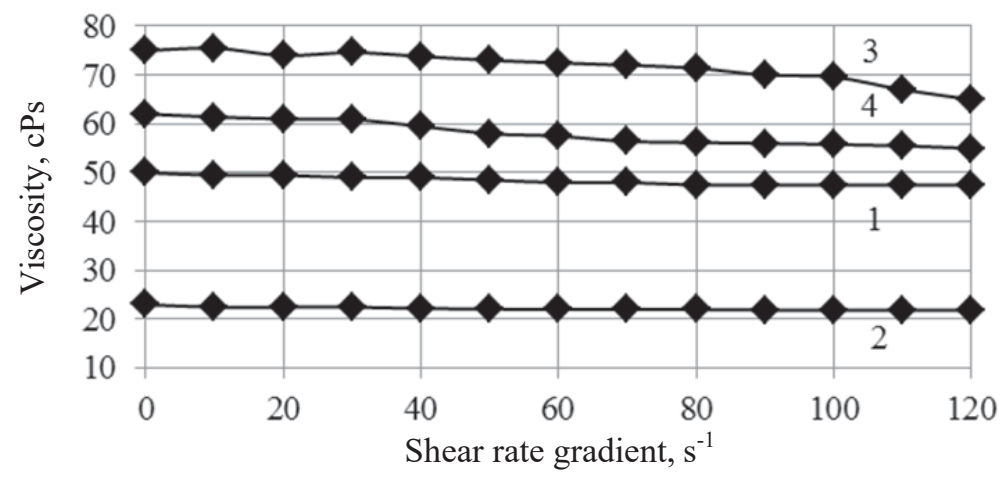

Fig. 1. Shear rate gradient dependence on viscosity of 1.5\% HPMC aqueous solutions: 1 is an aqueous solution of sample no. 1 prepared at $25^{\circ} \mathrm{C}, 2$ is an aqueous solution of sample no. 1 prepared at $100^{\circ} \mathrm{C}, 3$ is an aqueous solution of sample no. 2 prepared at $25^{\circ} \mathrm{C}, 4$ is an aqueous solution of sample no. 2 prepared at $100^{\circ} \mathrm{C}$. Measurements were carried out at $25^{\circ} \mathrm{C}$.

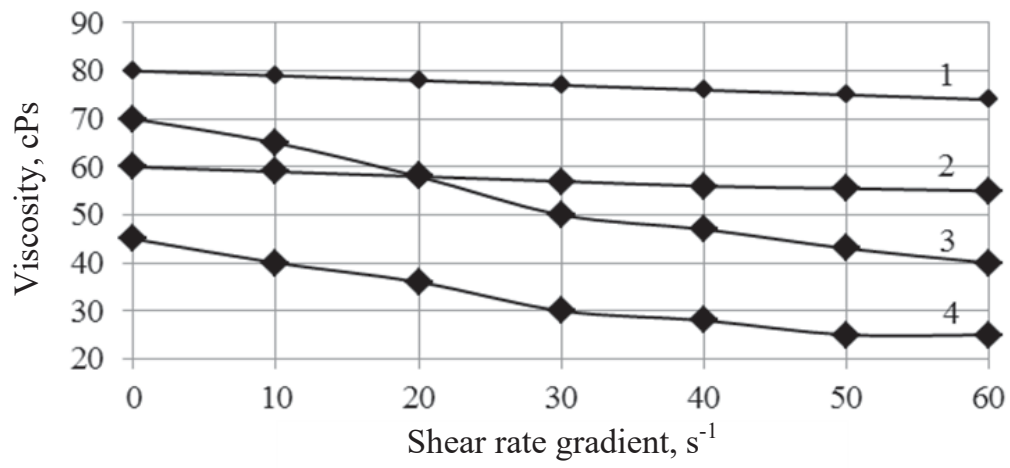

Fig. 2. Dependence of viscosity of $1.5 \%$ aqueous agar-agar solutions on shear rate gradient: 1 is an aqueous solution of sample no. 1 prepared at $25^{\circ} \mathrm{C}, 2$ is an aqueous solution of sample no. 1 prepared at $100^{\circ} \mathrm{C}, 3$ is an aqueous solution of sample no. 2 prepared at $25^{\circ} \mathrm{C}, 4$ is an aqueous solution of sample no. 2 prepared at $100^{\circ} \mathrm{C}$. Measurements were carried out at $25^{\circ} \mathrm{C}$. 
$70 \%$ depending on shear rate gradient. Furthermore, decrease in viscosity (Fig. 4) of carrageenan aqueous solutions with the measuring time increase at a constant shear rate gradient was observed. This fact may indicate structural changes in the carrageenan solution.

There may be a gradual decrease in the number of intermolecular contacts caused by molecular orientation in the direction of fluid flow during measurements (i. e., in circumferential directions). Thus, the studied aqueous solutions of natural polysaccharides can be classified by a degree of deviation from Newton's Law as shown in Table 1.

The results show that, under otherwise equal conditions, viscosity of aqueous solutions of natural polysaccharides may depend on the measurement procedure, parameters of which include measurement period and shear rate gradient. These results demonstrate that rheological properties exhibited by mixtures may be also influenced by parameters of processes used to produce biodegradable films. For example, when using a high proportion of carrageenan in mixtures it will be necessary to give special consideration to duration of the key process steps.

Important parameters that determine viscosity of aqueous solutions of high-molecular compounds are substance concentration, solution $\mathrm{pH}$, content of sodium chloride in the solution, and temperature. In this connection, we further analyzed dependence of rheological properties of aqueous solutions of natural polysaccharides on these factors.

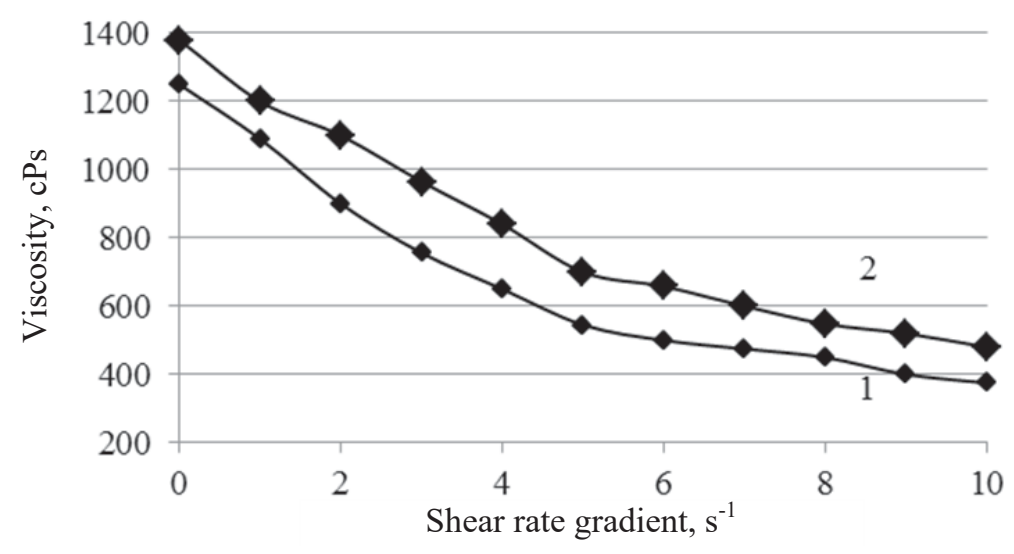

Fig. 3. Dependence of viscosity of $5.0 \%$ carrageenan aqueous solutions on shear rate gradient: 1 is an aqueous solution of sample no. 1 prepared at $25^{\circ} \mathrm{C}, 2$ is an aqueous solution of sample no. 2 prepared at $25^{\circ} \mathrm{C}$. Measurements were carried out at $25^{\circ} \mathrm{C}$.

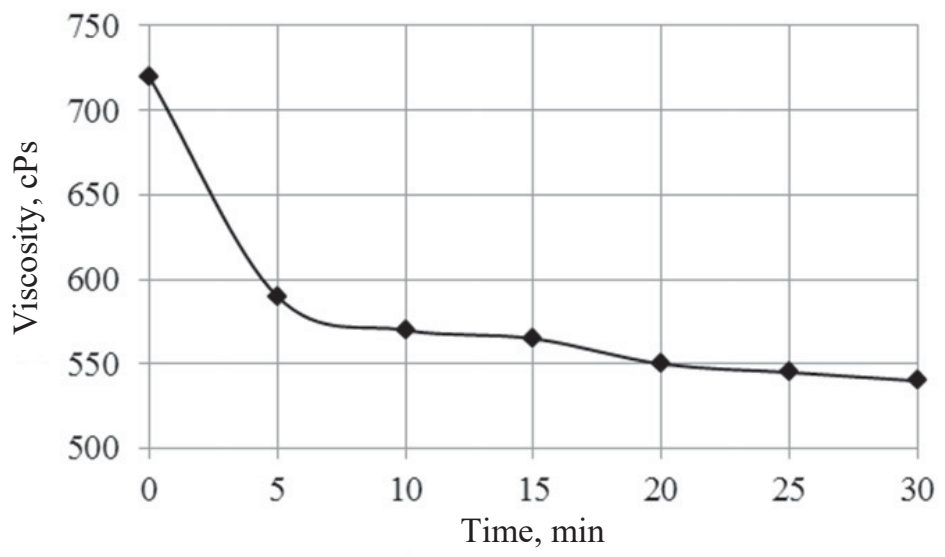

Fig. 4. Time dependence of viscosity of sample no. 2 of $5.0 \%$ carrageenan aqueous solution. Measurements were carried out at $25^{\circ} \mathrm{C}$ and a shear rate gradient of $5.0 \mathrm{~s}^{-1}$.

Table 1. Characteristics of rheological properties of aqueous solutions of natural polysaccharides by a degree of deviation from Newton's Law

\begin{tabular}{|l|l|}
\hline Substance & \multicolumn{1}{|c|}{ Characteristic of rheological properties of aqueous solutions } \\
\hline HPMC & $\begin{array}{l}\text { Deviations from Newton's Law are insignificant. } \\
\text { Depending on the measurement conditions, apparent viscosity varies by } 5-10 \% .\end{array}$ \\
\hline Agar-agar & $\begin{array}{l}\text { Deviations from Newton's Law are insignificant. } \\
\text { Depending on the measurement conditions, apparent viscosity varies by } 10-15 \% .\end{array}$ \\
\hline Carrageenan & $\begin{array}{l}\text { Significant deviations from Newton's Law. } \\
\text { Depending on viscosity measurement conditions, apparent viscosity may vary by } 70 \% . \\
\text { Viscosity decreased with the increase in the measurement period at a constant shear rate gradient. }\end{array}$ \\
\hline
\end{tabular}


Fig. 5 shows dependence of viscosity of hydroxypropyl methylcellulose aqueous solutions on HPMC concentration. Fig. 5 shows that dependences are not linear, but viscosity does not increase very sharply, making HPMC solutions within this range of concentrations similar in rheological properties to solutions with low molecular weight compounds.

Since conditions of preparation of polysaccharide solutions significantly affect their viscosity, Table 2 shows viscosity of solutions of the same concentrations, but prepared by heating to $100^{\circ} \mathrm{C}$. Data in Table 2 indicate that in both cases heating during solutions preparation results in a slight drop in solution viscosity.

Table 2. Dependence of viscosity of HPMC aqueous solutions on their concentration in solutions prepared at $25^{\circ} \mathrm{C}$ and $100^{\circ} \mathrm{C}$

\begin{tabular}{|c|c|c|c|c|}
\hline \multirow{2}{*}{ Sample } & \multirow{2}{*}{$\begin{array}{c}\text { Solution } \\
\text { preparation } \\
\text { conditions }\end{array}$} & \multicolumn{3}{|c|}{$\begin{array}{c}\text { Solution viscosity, cPs, } \\
\text { depending on concentration }\end{array}$} \\
\cline { 3 - 5 } no. 1 & $0.5 \mathrm{wt} \%$ & $1.0 \mathrm{wt} \%$ & $1.5 \mathrm{wt} \%$ \\
\cline { 2 - 5 } & $25^{\circ} \mathrm{C}$ & 9.4 & 14.8 & 44.8 \\
\hline \multirow{2}{*}{ no. 2} & $100^{\circ} \mathrm{C}$ & 7.9 & 13.1 & 38.2 \\
\cline { 2 - 5 } & $25^{\circ} \mathrm{C}$ & 15.3 & 40.7 & 75.2 \\
\cline { 2 - 5 } & $100^{\circ} \mathrm{C}$ & 14.9 & 38.6 & 72.7 \\
\hline
\end{tabular}

Fig. 6 shows dependence of agar-agar aqueous solutions viscosity on concentration.
Fig. 6 indicates that viscosity of agar-agar solutions increases almost linearly, which is characteristic for solutions of low molecular weight compounds.

Rheological properties are sensitive to changes in the molecular structure (microstructure) of materials. Table 3 shows that the sample no. 1 has a more pronounced viscosities compared to the sample no. 2, from which it can be concluded that sample no. 1 has a higher molecular weight and macromolecular length.

Table 3. Dependence of viscosity of samples of agaragar aqueous solutions on their concentration in solution prepared at $25^{\circ} \mathrm{C}$

\begin{tabular}{|c|c|c|c|c|}
\hline \multirow[t]{2}{*}{ Sample } & \multirow{2}{*}{$\begin{array}{c}\text { Solution } \\
\text { preparation } \\
\text { conditions }\end{array}$} & \multicolumn{3}{|c|}{$\begin{array}{l}\text { Solution viscosity, cPs, depending } \\
\text { on concentration }\end{array}$} \\
\hline & & $0.5 \mathrm{wt} \%$ & $1.0 \mathrm{wt} \%$ & $1.5 \mathrm{wt} \%$ \\
\hline no. 1 & $25^{\circ} \mathrm{C}$ & 24.0 & 45.0 & 80.5 \\
\hline no. 2 & $25^{\circ} \mathrm{C}$ & 18.0 & 36.0 & 69.5 \\
\hline
\end{tabular}

Carrageenan aqueous solutions exhibit pronounced properties characteristic for solutions of high-molecular compounds. Fig. 7 shows dependence of viscosity of carrageenan aqueous solutions on concentration.

A very sharp increase in viscosity with the concentration increase is observed. The ordinate axis represents the decimal logarithm of a measured viscosity, so that it is seen that viscosity of solutions increases by

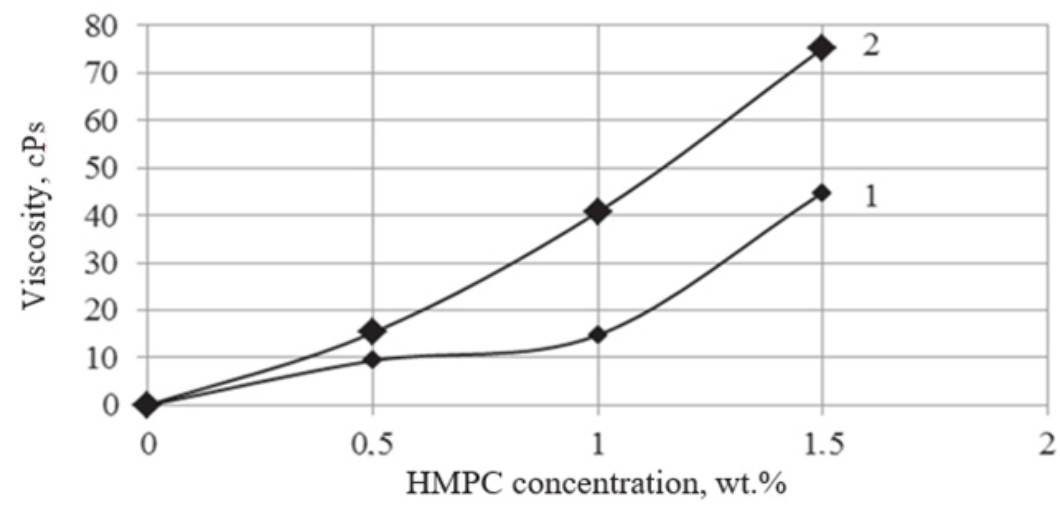

Fig. 5. Dependence of viscosity of HPMC aqueous solutions on concentration: 1 is an aqueous solution of sample no. 1 , prepared at $25^{\circ} \mathrm{C}, 2$ is an aqueous solution of sample no. 2 , prepared at $25^{\circ} \mathrm{C}$. Measurements were carried out at $25^{\circ} \mathrm{C}$.

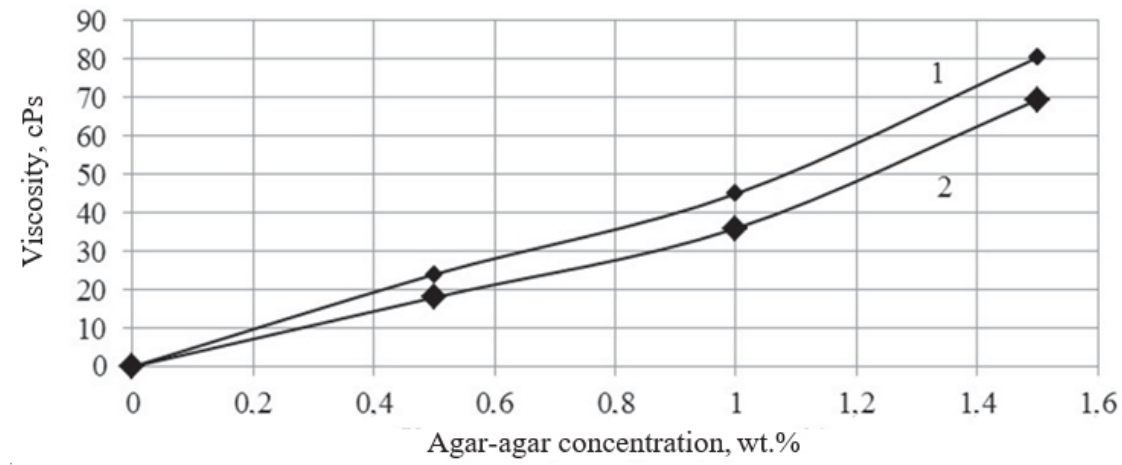

Fig. 6. Dependence of agar-agar aqueous solutions viscosity on concentration: 1 is an aqueous solution of the sample no. 1,2 is an aqueous solution of the sample no. 2 . Measurements were carried out at $50^{\circ} \mathrm{C}$. 
more than 3 orders of magnitude. In addition, the studied carrageenan solutions have thixotropic properties and are non-Newtonian fluids.

Table 4 shows the summary results of the studied viscosity of carrageenan aqueous solutions, prepared with different concentrations.

Table 4. Dependence of viscosity of carrageenan aqueous solutions on concentration.

\begin{tabular}{|c|c|c|c|c|}
\hline \multirow[t]{2}{*}{ Sample } & \multirow{2}{*}{$\begin{array}{c}\text { Solution } \\
\text { preparation } \\
\text { conditions }\end{array}$} & \multicolumn{3}{|c|}{$\begin{array}{l}\text { Solution viscosity, cPs, depending } \\
\text { on arrageenan concentration, wt. } \%\end{array}$} \\
\hline & & 1.0 & 3.0 & 5.0 \\
\hline no. 1 & $25^{\circ} \mathrm{C}$ & 1.5 & 15.5 & 1250.0 \\
\hline no. 2 & $25^{\circ} \mathrm{C}$ & 2.1 & 18.3 & 1380.0 \\
\hline
\end{tabular}

Fig. 8 shows dependence of viscosity of HPMC aqueous solutions on $\mathrm{pH}$. From the Fig. 8 it follows that viscosity of HPMC solutions prepared at $25^{\circ} \mathrm{C}$ decreases with $\mathrm{pH}$ increase to a particular value, and then increases. This behavior can be caused by a change in the charge state of HPMC molecules.

From the Fig. 8 it is also clear that viscosity of HPMC aqueous solutions is decreased if subjected to heating at $\mathrm{pH}$. The reason is that HPMC solutions with $\mathrm{pH} 5$ are stable at $23-25^{\circ} \mathrm{C}$. Hydrolysis of ester groups in the temperature increase is characterized by splitting a polymer chain. $\beta$-splitting occurs only for glycosidic links, which are adjacent to the esterified carboxylic group. Depolymerization and deesterification at $\mathrm{pH}$ 6 accelerate even at $23-25^{\circ} \mathrm{C}$, speed of these reaction is directly proportional to $\mathrm{pH}$. Destruction of HPMC molecules occurs more rapidly at higher temperatures.

Table 5 summarizes viscosity results for hydroxypropyl methylcellulose aqueous solutions, prepared at $25^{\circ} \mathrm{C}$ and at $100^{\circ} \mathrm{C}$, under appropriate $\mathrm{pH}$. It can be seen that in both cases heating in the preparation process causes a drop in viscosity of solutions; the higher $\mathrm{pH}$, the greater viscosity decrease is. Thus, at $\mathrm{pH}$ 6, viscosity value is 40 times smaller. Instability of HPMC solutions at $\mathrm{pH} 6$ and elevated temperatures must be considered when developing processes for production of biodegradable films.

Table 5. Dependence of viscosity of HPMC aqueous solutions on $\mathrm{pH}$

\begin{tabular}{|c|c|c|c|c|c|c|}
\hline \multirow{2}{*}{ Sample } & \multirow{2}{*}{$\begin{array}{c}\text { Solution } \\
\text { preparation } \\
\text { conditions }\end{array}$} & \multicolumn{5}{|c|}{$\begin{array}{c}\text { Solution viscosity, cPs, } \\
\text { depending on } \mathrm{pH}\end{array}$} \\
\cline { 3 - 7 } & 2.0 & 3.0 & 4.0 & 5.0 & 6.0 \\
\hline \multirow{2}{*}{ no. 1} & $25^{\circ} \mathrm{C}$ & 40.9 & 40.3 & 31.1 & 37.1 & 42.9 \\
\cline { 2 - 7 } & $100^{\circ} \mathrm{C}$ & 33.0 & 35.9 & 29.4 & 23.7 & 8.95 \\
\hline \multirow{2}{*}{ no. 2} & $25^{\circ} \mathrm{C}$ & 74.6 & 71.7 & 70.4 & 67.6 & 77.5 \\
\cline { 2 - 7 } & $100^{\circ} \mathrm{C}$ & 70.1 & 67.6 & 66.4 & 63.8 & 62.4 \\
\hline
\end{tabular}

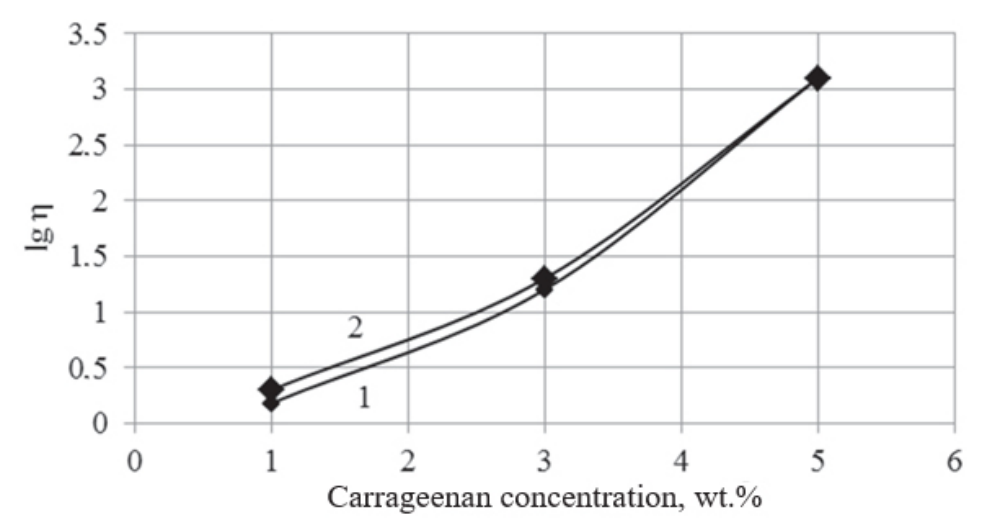

Fig. 7. Dependence of viscosity of carrageenan aqueous solutions on concentration: 1 is an aqueous solution of the sample no. 1,2 is an aqueous solution of the sample no. 2 . Measurements were carried out at $25^{\circ} \mathrm{C}$.

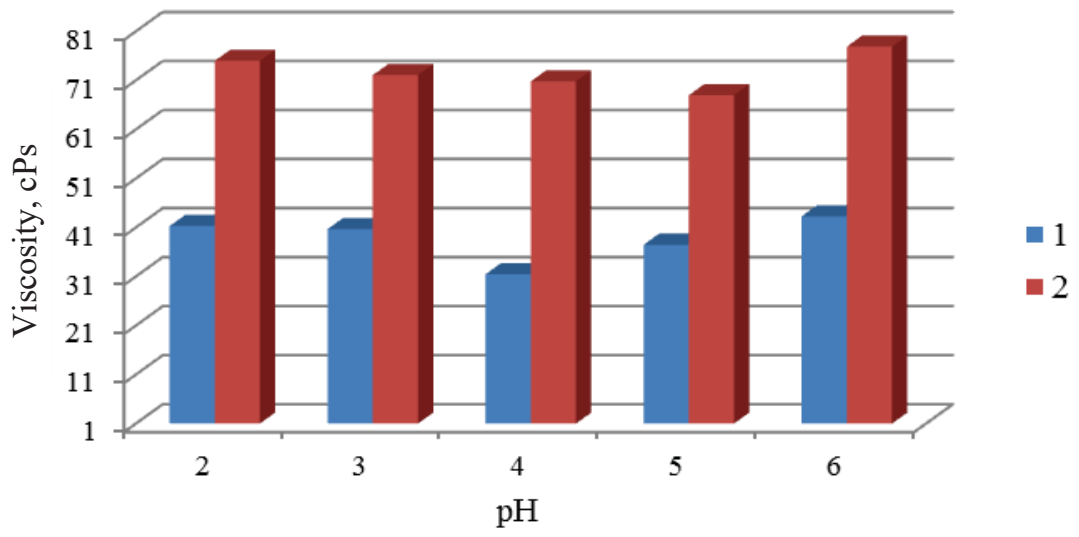

Fig. 8. Dependence of viscosity of HPMC solutions on $\mathrm{pH}$ : 1 is an aqueous solution of sample no. 1 , prepared at $25^{\circ} \mathrm{C}$, 2 is an aqueous solution of sample no. 2 , prepared at $25^{\circ} \mathrm{C}$. Measurements were carried out at $25^{\circ} \mathrm{C}$. 
Fig. 9 summarizes the results of measuring the dynamic viscosity of agar-agar aqueous solutions at different values of $\mathrm{pH}$. $\mathrm{pH}$ of solutions were ranged from 3.0 to 7.0. Initially viscosity of samples was measured at $50^{\circ} \mathrm{C}$, but part of polysaccharides began to form gel during measurements. Viscosity for them was measured at $70^{\circ} \mathrm{C}$.

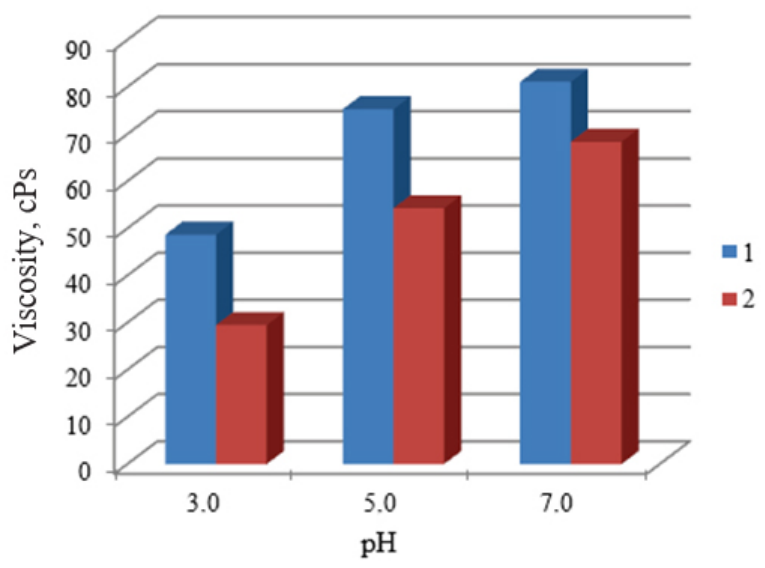

Fig. 9. Dependence of viscosity of samples of agaragar aqueous solutions on $\mathrm{pH}: 1$ is an aqueous solution of the sample no. 1 , prepared at $25^{\circ} \mathrm{C}, 2$-is an aqueous solution of the sample no. 2 , prepared at $25^{\circ} \mathrm{C}$. Measurements were carried out at $50^{\circ} \mathrm{C}$ and $70^{\circ} \mathrm{C}$

Data in Table 6 show that in both cases dynamic viscosity of agar-agar solutions increases with $\mathrm{pH}$.

Table 6. Dependence of viscosity of samples of agaragar aqueous solutions (1.5\%) on $\mathrm{pH}$

\begin{tabular}{|c|c|c|c|c|}
\hline \multirow{2}{*}{ Sample } & \multirow{2}{*}{$\begin{array}{c}\text { Measurement } \\
\text { conditions }\end{array}$} & \multicolumn{4}{|c|}{$\begin{array}{c}\text { Solution viscosity, cPs, } \\
\text { with respect to } \mathrm{pH}\end{array}$} \\
\cline { 3 - 5 } & & 3.0 & 5.0 & 7.0 \\
\hline no. 1 & $50^{\circ} \mathrm{C}$ & 48.7 & 75.3 & 81.1 \\
\hline no. 2 & $70^{\circ} \mathrm{C}$ & 29.5 & 54.3 & 68.4 \\
\hline
\end{tabular}

Fig. 10 shows dependence of carrageenan solution viscosity on $\mathrm{pH}$ value.

From Fig. 10 it follows that viscosity of carrageenan solutions decreases with $\mathrm{pH}$ increase to a specific value and then increases. This behavior can be caused by a change in the charge state of carrageenan molecules.

The content of salts (electrolytes) in hydroxypropyl methylcellulose solutions may affect their viscosity. Table 7 summarizes the results of measurement of dynamic viscosity of HPMC aqueous solutions containing an appropriate concentration of sodium chloride and prepared at $25^{\circ} \mathrm{C}$ and $100^{\circ} \mathrm{C}$. There is a small, almost linear increase in viscosity with increasing a salt concentration. It should be noted that viscosity changes are not so significant in view of sufficiently high maximum concentration of sodium chloride $-5 \%$. Heating solution in the course of preparation lowers viscosity but electrolyte addition regularities in solution remain similar.

Table 7. Dependence of viscosity of HPMC aqueous solutions on the content of sodium chloride in solution

\begin{tabular}{|c|c|c|c|c|c|}
\hline \multirow{2}{*}{ Sample } & \multirow{2}{*}{$\begin{array}{c}\text { Solution } \\
\text { preparation } \\
\text { conditions }\end{array}$} & \multicolumn{4}{|c|}{$\begin{array}{c}\text { Solution viscosity, cPs, } \\
\text { depending on concentration } \\
\text { of sodium chloride, wt. \% }\end{array}$} \\
\cline { 3 - 6 } & 0.0 & 1.0 & 3.0 & 5.0 \\
\hline \multirow{2}{*}{ no. 1} & $25^{\circ} \mathrm{C}$ & 44.5 & 47.3 & 44.0 & 45.4 \\
\cline { 2 - 6 } & $100^{\circ} \mathrm{C}$ & 38.2 & 41.4 & 40.1 & 35.9 \\
\hline \multirow{2}{*}{ no. 2} & $25^{\circ} \mathrm{C}$ & 75.2 & 74.8 & 73.6 & 75.8 \\
\cline { 2 - 6 } & $100^{\circ} \mathrm{C}$ & 69.5 & 68.3 & 67.1 & 70.7 \\
\hline
\end{tabular}

Table 8 summarizes the results of determination of viscosity of agar-agar aqueous solutions with different contents of sodium chloride. From Table 8 it follows that rheological properties of agar-agar aqueous solutions are practically independent of content of sodium chloride of up to 5.0 wt. $\%$.

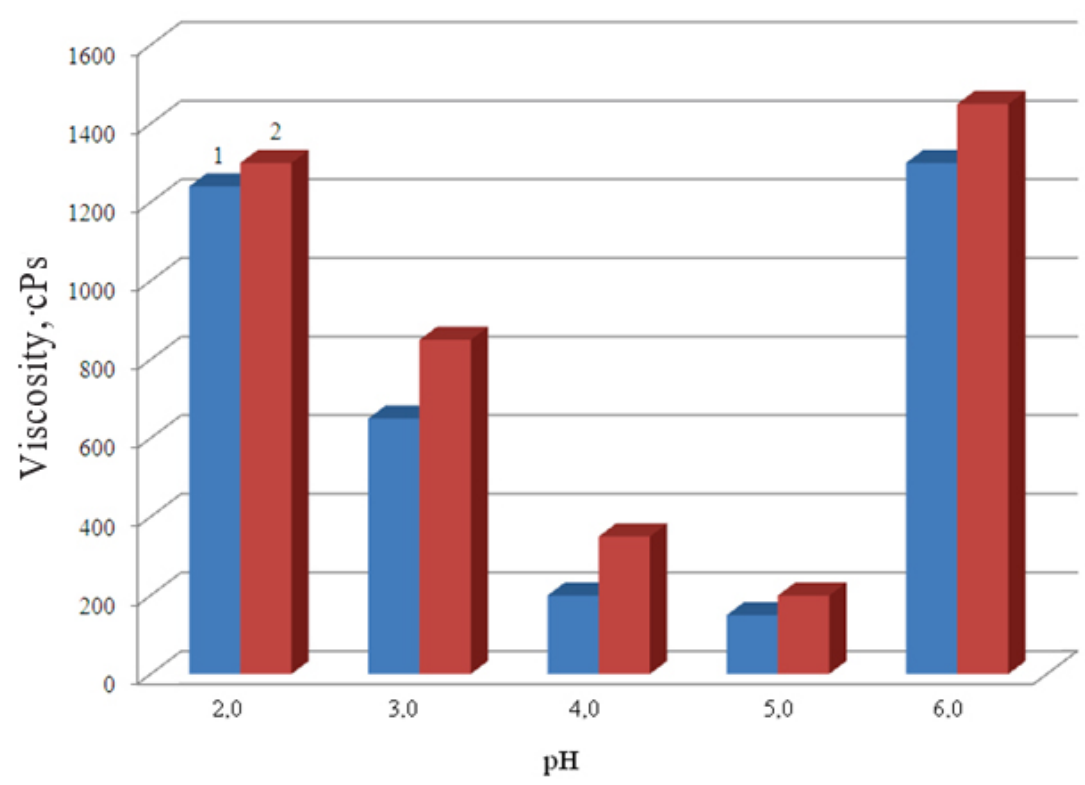

Fig. 10. Dependence of carrageenan solution viscosity on $\mathrm{pH}$ value: 1 is an aqueous solution of the sample no. 1 , prepared at $25^{\circ} \mathrm{C}, 2$ is an aqueous solution of the sample no. 2 , prepared at $25^{\circ} \mathrm{C}$ Measurements were carried out at $25^{\circ} \mathrm{C}$. 
Table 8. Dependence of viscosity of agar-agar aqueous solutions on sodium chloride content (measurements were carried out at $70^{\circ} \mathrm{C}$ )

\begin{tabular}{|c|c|c|c|c|c|}
\hline \multirow{2}{*}{ Sample } & \multirow{2}{*}{$\begin{array}{c}\text { Measurement } \\
\text { conditions }\end{array}$} & \multicolumn{4}{|c|}{$\begin{array}{c}\text { Solution viscosity, cPs, } \\
\text { depending on concentration } \\
\text { of sodium chloride, wt. \% }\end{array}$} \\
\cline { 3 - 6 } & & 0.0 & 1.0 & 3.0 & 5.0 \\
\hline no. 1 & $70^{\circ} \mathrm{C}$ & 78.5 & 80.8 & 81.2 & 79.4 \\
\hline no. 2 & $70^{\circ} \mathrm{C}$ & 67.7 & 70.4 & 68.5 & 69.0 \\
\hline
\end{tabular}

The sodium chloride content has a significant effect not only on viscosity of agar-agar aqueous solutions both on their pour point. Solution of the sample no. 2 with $5 \% \mathrm{NaCl}$ is gelled already at $75^{\circ} \mathrm{C}$, even with vigorous stirring. When reheating to $100^{\circ} \mathrm{C}$, gel does not dissolve. Solution of the sample no. 1 with $5 \%$ concentration of $\mathrm{NaCl}$ is gelled at a temperature of $50^{\circ} \mathrm{C}$.

Table 9 summarizes the results of determination of viscosity of carrageenan aqueous solutions with different salt contents. It is seen that viscosity in most weakly depends on salt concentration.

Table 9. Dependence of viscosity of carrageenan aqueous solutions $(1.5 \%)$ on sodium chloride content

\begin{tabular}{|c|c|c|c|c|c|}
\hline \multirow{2}{*}{ Sample } & \multirow{2}{*}{$\begin{array}{c}\text { Measurement } \\
\text { conditions }\end{array}$} & \multicolumn{4}{|c|}{$\begin{array}{c}\text { Solution viscosity, cPs, } \\
\text { depending on concentration } \\
\text { of sodium chloride, wt. \% }\end{array}$} \\
\cline { 3 - 6 } & & 0.0 & 1.0 & 3.0 & 5.0 \\
\hline no. 1 & $70^{\circ} \mathrm{C}$ & 12.2 & 12.7 & 12.9 & 13.4 \\
\hline no. 2 & $70^{\circ} \mathrm{C}$ & 9.8 & 10.1 & 10.4 & 10.8 \\
\hline
\end{tabular}

$\mathrm{NaCl}$ content has a significant influence on the pour point of carrageenan solutions and has less effect on viscosity. Sample no. 2 with $5 \% \mathrm{NaCl}$ is gelled already at $75^{\circ} \mathrm{C}$, even with vigorous stirring. When reheating to $100^{\circ} \mathrm{C}$, gel does not dissolve. Sample no. 1 with $5 \%$ $\mathrm{NaCl}$ is gelled at $50^{\circ} \mathrm{C}$.

Carrageenans are able to form gels at room temperature in sufficiently low concentrations (from $0.5 \%$ ) and can be recommended to be added to a process mixture as gelling agents.

According to the analysis of rheological properties of aqueous solutions of natural polysaccharides, the following conclusions can be drawn:

1. Aqueous solutions of HPMC behave similarly with solutions of low molecular weight compounds. The HPMC sample no. 2 has the highest viscosity. For $1.0-1.5 \%$ aqueous solutions, viscosity is in the range of $8,0-80,0 \mathrm{cPs}$. Heating to $100^{\circ} \mathrm{C}$ during preparation causes decrease in viscosity of HPMC solutions. Heating $\mathrm{HPMC}$ solutions to $100^{\circ} \mathrm{C}$ at $\mathrm{pH} 6$ leads to irreversible destruction of molecules.

2. Rheological characteristics of agar-agar aqueous solutions, measured at $50-70^{\circ} \mathrm{C}$ are similar to those for HPMC solutions. Agar-agar is capable to form a gel at room temperature at sufficiently low concentrations with $0.5 \%$ in contrast to HPMC, and can be recommended in the production of biodegradable polymers as a gelling agent.

3. Viscosity of $3.0-5.0 \%$ carrageenan aqueous solutions varies over a wide range from 1.5 to $1400.0 \mathrm{cPs}$. Viscosity of carrageenan aqueous solutions decreases to $\mathrm{pH} 5.0$ and then begins to increase with $\mathrm{pH}$ increase. $\mathrm{NaCl}$ content has a significant effect on the pour point of carrageenan solutions and less on their viscosity. Thus, it is possible to adjust viscosity of a process mixture in different directions in the production of biodegradable polymers over a wide range, selecting carrageenan with certain modifications.

\section{REFERENCES}

1. Kurt A., Kahyaoglu T. Characterization of a new biodegradable edible film made from salep glucomannan. Carbohydrate polymers, 2014, vol. 104, pp. 50-58. doi: 10.1016/j.carbpol.2014.01.003.

2. Oliviero M., Sorrentino L., Cafiero L. Foaming behavior of bio-based blends based on thermoplastic gelatin and poly (butylene succinate). J. of Appl. Polymer. Science, 2015, vol. 132, no. 48, pp. 2290-2298. doi: 10.1002/app.42704.

3. Volkov V.S. Anizotropiya v nelineynoy reologii polimerov [Anisotropy in nonlinear polymer rheology]. Vysokomolekulyarnye soedineniya [Macromolecular compounds], 2014, vol. 56, no. 5, pp 575-581. doi: 10.1134/S0965545X14050162.

4. Ol'khov A.A, Gol'dshtrakh M.A., Ishchenko A.A., Iordanskiy A.L. Obrazovanie kompleksov v smesyakh na osnove poligidroksibutirata $\mathrm{i}$ polietilenglikolya [Formation of complexes in mixtures based on polyethylene glycol and polyhydroxybutyrate]. Khimicheskaya fizika [Chemical physics], 2015, vol. 34, no. 11, pp. 63-72.

5. Prosekov A.Yu., Ul'rikh E.V., Babich O.O., Dyshlyuk L.S. Issledovanie koeffitsienta integral'nogo svetopropuskaniya i tolshchiny plenok iz farmatsevticheskogo zhelatina i ego rastitel'nykh analogov [Studies of the integral light transmittance and thickness of films from the pharmacetical gelatin and its plant analogs]. Fundamental'nye issledovaniya [Fundamental studies], 2014, no. 9, pp. 2411-2415.

6. Korotkaya E.V., Prosekov A.Yu. A method for producing a collodion film by centrifugal Patent, no. 2011109728/052011, 2012.

7. Slivkin A.I., Belenova A.S., Shatalov G.V. Izuchenie svoystv rastvorov khitozana [Studying of chitosan solutions properties]. Vestnik Voronezhskogo gosudarstvennogo universiteta, Seriya: Khimiya. Biologiya. Farmatsiya [Bulletin of Voronezh State University Series: Chemistry. Biology. Pharmacy], 2014, no. 1, pp. 134-137.

8. Prosekov A.Yu., Ul'rikh E.V., Babich O.O., Sukhikh S.A. Reologicheskie svoystva rastitel'nykh analogov farmatsevticheskogo zhelatina [Rheological properties of plant analogues of pharmaceutical gelatin]. Fundamental'nye issledovaniya [Fundamental studies], 2013, no.10-15, pp. 3384-3388.

9. Chursin V.I. Reologiya organovodnykh rastvorov biopolimera i kharakteristika plenok [Rheology of organowater biopolymer solutions and feature of films]. Dizayn i tekhnologii [Design and technology], 2012, vol. 28., no. 70, pp. 52-58.

10. Ahmed J., Hiremath N., Jacob H. Antimicrobial, Rheological, and Thermal Properties of Plasticized Polylactide Films Incorporated with Essential Oils to Inhibit Staphylococcus aureus and Campylobacter jejuni. J. of Food Science, 2016, vol. 81, no. 2, pp. 419-429. doi: 10.1111/1750-3841.13193. 
11. Amonova D.M., Mukhamedzhanova M.Yu., Shomurotov Sh.A., Turaev A.S. Reologicheskie svoystva kontsentrirovannykh vodnykh rastvorov gidrolizovannykh proizvodnykh galaktomannana [Rheological properties of concentrated aqueous solutions of hydrolysed galactomannan derivatives]. Khimiya rastitel'nogo syr'ya [The Chemistry of Plant Raw Materials Academic Journal], 2014, no. 4, pp. 67-75.

12. Mantia La F.P., Mistretta M.C., Palermo S. Morphology, rheology, and mechanical properties of a new nanobiocomposite. J. of Appl Polymer Science, 2015, vol. 132, no. 25, pp. 1829-1839. doi: 10.1002/app.42128.

13. Mikesova J., Hasek J., Tishchenko G. Rheological study of chitosan acetate solutions containing chitin nanofibrils. Carbohydrate polymers, 2014, vol. 112, pp. 753-757. doi: 10.1016/j.carbpol.2014.06.043.

14. Swain S.K., Patra S.K., Kisku S.K. Study of thermal, oxygen-barrier, fire-retardant and biodegradable properties of starch bionanocomposites. Polymer composites, 2014, vol. 35, no. 7, pp. 1238-1243.

15. Ferrarezi F.M.M., Rodrigues G.V., Felisberti M.I. Investigation of cellulose acetate viscoelastic properties in different solvents and microstructure. European Polymer J., 2013, vol. 49, no. 9, pp. 2730-2737.

16. Asyakina L.K., Prosekov A.Yu., Ul'rikh E.V., Belova D.D. Issledovanie degradatsii plenok i kapsul iz rastitel'nykh analogov farmatsevticheskogo zhelatina [Study of degradation of films and capsules plant analogs pharmaceutical gelatine]. Fundamental'nye issledovaniya [Fundamental studies], 2014, no. 9, pp. 2369-2374.

\section{Lyudmila K. Asyakina}

Research associate of the Department of Bionanotechnology, Kemerovo Institute of Food Science and Technology (University),

Kemerovo, Russian Federation

\section{Lyubov S. Dyshlyuk}

Cand.Sci.(Biol.), Senior Lecturer of the Department of Bionanotechnology, Kemerovo Institute of Food Science and Technology (University), Kemerovo, Russian Federation 